\title{
Identified need for improving post abortion care in Namibia
}

\author{
Nghitanwa Emma Maano*, Hatupopi Saara Kerthu \\ Midwifery Department, Faculty of Health Sciences, University of Namibia, Namibia
}

Received: November 27, 2019

DOI: $10.5430 / \mathrm{cns} . v 8 \mathrm{n} 2 \mathrm{p} 10$
Accepted: March 10, 2020

Online Published: April 20, 2020

\begin{abstract}
Globally, about 75 million women have undergone abortions which is either induced or spontaneous and require post abortion care (PAC). Out of the 75 million abortions, 44 million are induced, while 31 million are miscarriages which occur spontaneously. Furthermore, half of the induced abortions are performed by unskilled people in a non-hygienic environment which make them unsafe and dangerous to the women.The World Health Organization recommends that all women who had abortion should receive PAC to prevent ill health and deaths related to complications of abortions. However, in Namibia, the status of PAC is unknown as there is no study conducted in this regard. Moreover, PAC is only conducted by medical doctors in the district hospitals and no nurses or midwives are trained on PAC services. A mini literature review was conducted on PAC globally and in Namibia.
\end{abstract}

Key Words: Post abortion, Care, Need, Improving

\section{INTRODUCTION}

PAC is included in the maternity care package that should be provided from the primary health care level to the women in need and it refers to a specific set of services rendered to women after spontaneous or induced abortion. ${ }^{[1]}$ The incidents of abortions are higher in developing countries than developed countries ${ }^{[2]}$ and there is poor service of post abortion care (PAC) which leads to about 68,000 women to die annually due to untreated or inadequately treated PAC. ${ }^{[3]}$ According to the $\mathrm{WHO}^{[4]}$ about 21.6 million of unsafe abortions occur worldwide in 2008 whereby about 21.2 million occurred in developing countries. Most women in the developing countries often perform unsafe abortions due to restrictive abortion legislation that lead to increase in maternal deaths and higher numbers of women who will suffer long-term health complications. This paper is based on the mini literature review conducted on PAC where by articles on PAC was retrieved from data bases and reviewed.

\section{GLOBAL Status OF POST ABORTion CARE}

About 67,000 women in the developing countries globally die due to untreated or not rendered proper PAC. ${ }^{[5]}$ Post abortion complications are mostly prevalent in poverty stricken communities and in the countries with restricted abortion legislations. ${ }^{[6]}$

PAC should include emergency treatment for complications related to spontaneous or induced abortions, provision of family planning and pregnancies spacing and counselling. PAC also includes services such as assessment and diagnoses of sexually transmitted infections, including HIV/AIDS. ${ }^{\text {[7] }}$ According to the College of American Obstetrics and Gynaecologists, ${ }^{[6]}$ community mobilization and partnership in

\footnotetext{
*Correspondence: Nghitanwa Emma Maano; Email: enghitanwa@unam.na; Address: Midwifery Department, Faculty of Health Sciences, University of Namibia, Namibia.
} 
prevention unwanted pregnancies and unsafe abortions, and information on timely and appropriate care of PAC is an integral part of PAC services.

Implementing PAC services would help addressing the challenges caused by unsafe abortion complications, reduce maternal ill health and mortality, and improve women's reproductive health. According to the United States Agency for International Development (USAID), ${ }^{[8]}$ PAC can be implemented in any country and women should rendered PAC regardless of whether abortion is legal or not legal in the country. This is important as PAC deals with treating a woman after she had experienced an induced abortion or miscarriage. Moreover, by providing quality PAC service it is a relatively simple, effective, and cost efficient way to lower maternal death rates as complications caused by abortions could be prevented. ${ }^{[9]}$ With the absence of PAC services in some countries women not treated after abortion may end up dying due to abortion complications or may live with health problems such as chronic pain, chronic pelvic inflammatory disease, and infertility as a result of incomplete abortion which may also lead to social problems such as marital of family conflicts. Nevertheless, most mortality and morbidities resulting from abortion complications are preventable. $^{[10]}$

In countries where abortion is not legalised such as Namibia women who had induced the abortion may be reluctant to visit the health facilities for PAC as they have fear of being discovered and eager to ensure that their unwanted pregnancy has been terminated and they might also have psychological needs. In addition, women who have spontaneous abortion or miscarriage are experiencing the grief of pregnancy loss because the pregnancy was desired or planned. ${ }^{[11]}$ Therefore, PAC services should not only consider physical or physiological needs but should also include psychological needs.

In addition to the provision of PAC services by the medical doctor, PAC services could be safely provided by a nurse or midwife after received a proper PAC service training ${ }^{[7]}$ so that PAC should be decentralized to secondary hospitals and primary health care centers. Health care workers are also experiencing challenges in PAC provision. Geese, Kabiru, Sidze, Muuo and Izugbara ${ }^{[12]}$ conducted a study among Kenyan health care workers to assess the challenges they encounter in PAC provision. The study reveals different challenges such as non conducive working environment for PAC, stigmatization of health workers offering PAC by the public and other health workers, ambiguous abortion law, poor staffing, shortage of providers trained in PAC, and lack of essential PAC equipment (such as manual vacuum aspirators); medications, and supplies. One participant indicated

Published by Sciedu Press the challenge she faced after provided PAC service to young inpatient woman as she was apprehended by the traditional chief and the patient's parents and later arrested for offering PAC services; fortunately she was released because of the assistance by the medical officer. Those challenges are negatively affecting the provision and quality of PAC services offered by the healthcare workers.

According to the United States Agency for International Development, ${ }^{[8]}$ Vacuum aspiration, either manual vacuum aspiration (MVA) or electric vacuum aspiration (EVA) should be used in PAC as is safer and less painful than sharp curettage, which is usually performed with general anaesthesia in theatre. Furthermore, vacuum aspiration (electric or manual) is associated with less pain and significantly less blood loss than sharp curettage. In addition, the use of general anaesthesia with sharp curettage is associated with cervical injury, uterine perforation, and subsequent abdominal haemorrhage. ${ }^{[7]}$ It was also confirmed by several studies that, the use of Misoprostol for uterine evacuation during PAC services is an effective and safest way. ${ }^{[12-15]}$ Therefore it is safer to use vacuum aspiration (EVA) or manual vacuum aspiration (MVA) and Misoprostol to evacuate the uterus rather than using curettage and to provide appropriate PAC. These methods make it safer for PAC services to be rendered by the trained midwives or nurses even at the primary health care settings which make PAC services to be accessible in the community.

\section{PAC in Namibia}

In Namibia, the Abortion and Sterilization Act ${ }^{[16]}$ states that abortion is only allowed in case of rape, fetal malformation, danger to a woman's life, and for harm to woman's physical and mental health. However, illegal abortions remain reported at higher rates in the newspapers on daily bases and become a major health problem in Namibia. Women have fear of seeking health care after abortion, either induced or not. Maternal mortality rate in Namibia was 385/100,000 in 2013 and complication related to abortion is one of the top causes. ${ }^{[17]}$ Furthermore, the Reproductive health policy of Namibia stated its aim as establishment and delivering effective primitive, preventive, curative and rehabilitative reproductive health service in all facilities and a community level by providing PAC. However there is a dearth of guidelines related to PAC services in Namibia. In addition, no study related to PAC was conducted in Namibia before. In addition, the state of PAC service in Namibia is unknown as there is no study conducted in this aspect and there is minimal information of PAC services in the Reproductive health policy. ${ }^{[18]}$ Furthermore, there is no mentioning of PAC services in the scope of the Registered nurse/ midwife. ${ }^{[19]}$ 


\section{Conclusions}

The review revealed the need to conduct a study to investigate the status of PAC service in Namibia aiming at improving PAC service in Namibia. By conducting a study on PAC service in Namibia we expect to obtain positive results of program impact as Namibian women experience greater risk of complications after abortion due to lower levels of support than counterparts in developed countries. The study outcome would improve PAC services in Namibia and contribute to the reduction of maternal mortality rates and prevention of post abortion complications. The results will also inform policy makers and other stakeholders in improving PAC in Namibia. As there is no study conducted in PAC in Namibia, the scientific results will assist informing practice such as reviewing the scope of practice of nurses to include PAC services and developing policies and guidelines supporting the availability of PAC services in all levels of care as per WHO guidelines. ${ }^{[20]}$

\section{CONFlicts OF INTEREST Disclosure}

The authors declare they have no conflicts of interest.

\section{REFERENCES}

[1] Owolabi OO, Biddlecom A, Whitehead HS. Health systems' capacity to provide post-abortion care: a multi country analysis using signal functions. Lancet Glob Health. 2019; 7: e110-18. https : //doi.org/10.1016/S2214-109X (18)30404-2

[2] World Health Organization. Health worker roles in providing safe abortion care and post-abortion contraception. Geneva: World Health Organization; 2015 [Accessed at 20 July 2016]. Available from: http://www.who.int/reproductivehealth/publica tions/unsafe_abortion/abortion-task-shifting/en/

[3] AlRifai A. Assessment of Safe and Unsafe Abortion among Palestinian Women in Hebron Governorate in Southern West Bank- Palestine. International Planned Parenthood Federation. 015. Available from: https://www.safeabortionwomensright.or g/wp-content/uploads/2016/05/Family-Planning-and-P rotection-Association-Final.pdf

[4] World Health Organization (WHO). Unsafe Abortion: Global and Regional Estimates of the Incidence of Unsafe Abortion and Associated Mortality in 2008, 6th ed. Geneva: World Health Organization. 2011 Available from: https://www.who.int/reproductivehealth /publications/unsafe_abortion/9789241501118/en/

[5] Grimes DA, Benson J, Singh S, et al. Unsafe abortion: the preventable pandemic. The Lancet Sexual and Reproductive Health Series. 2006. https://doi.org/10.1016/S0140-6736(06)69481-6

[6] American College of Obstetrician and Gynecologist. Misoprostol for post abortion care. Committee on international affairs no.427. 2009 Available from: https://www.who.int/selection_medicine s/committees/expert/17/application/ACOG_ref.pdf

[7] Huber D, Curtis C, Irani C, et al. Post abortion Care: 20 Years of Strong Evidence on Emergency Treatment, Family Planning, and Other Programming Components Twenty Global Health: Science and Practice. 2016; 4(3): 481-494. PMid: 27571343. https : //doi.org/10.9745/GHSP-D-16-00052

[8] United States Agency for International Development (USAID). Post abortion Care Working Group. What works: a policy and program guide to the evidence on post abortion care. Washington (DC): USAID. 2007. Available from: http://www.postabortioncare.o $\mathrm{rg} / \mathrm{sites} / \mathrm{pac} / \mathrm{files} / \mathrm{Compendium}$.pdf

[9] Kappa N, Whyteb P, Tangc J, et al. A review of evidence for safe abortion care. Contraception. 2013; 88(3): 350-363. PMid: $23261233 \mathrm{ht}$ tps://doi.org/10.1016/j.contraception.2012.10.027
[10] Corbett MR, Turner KL. Essential elements of post abortion care: origins, evolution and future directions. International Family Planning Perspectives. 2003; 29(3): 106-11. Available from: https: //doi.org/10.2307/3181075

[11] Nynas J, Narang P, Kolikonda MK, et al. Depression and Anxiety Following Early Pregnancy Loss: Recommendations for Primary Care Providers Prim Care Companion CNS Disord. 2015; 17(1). PMid: 26137360. https://doi.org/10.4088/PCC.14r01721

[12] Blandine T, Ouattara AZ, Coral A, et al. Sublingual misoprostol as first-line care for incomplete abortion in Burkina Faso.Int $\mathrm{J}$ Gynaecol Obstet. 2012; 119(2): 166-169. Available from: https : //www.ncbi.nlm.nih.gov/pubmed/22935621

[13] Montesinos R, Durocher J, Leon W, et al. Oral misoprostol for the management of incomplete abortion in Ecuador.Int J Gynaecol Obstet. 2011; 115(2): 135-139. PMid: 21872244. Available from: https://doi.org/10.1016/j.ijgo.2011.06.015

[14] Shochet T, Diop A, Gaye A, et al. Sublingual misoprostol versus standard surgical care for treatment of incomplete abortion in five sub-Saharan African countries. BMC Pregnancy Childbirth. 2012; 12(1): 127. PMid: 23150927. Available from: https://doi.org/ 10.1186/1471-2393-12-127

[15] Taylor J, Diop A, Blum J, et al. Oral misoprostolas an alternative to surgical management for incomplete abortion in Ghana.Int J Gynaecol Obstet. 2011; 112(1): 40-44. PMid: 21122848. Available from: https://doi.org/10.1016/j.ijgo.2010.08.022

[16] Republic of Namibia. Abortion and Sterilization Act. 1975. Namprint.

[17] The Nambia Ministry of Health and Social Services (MoHSS) and ICF International. The Namibia Demographic and Health Survey 2013. Windhoek, Namibia, and Rockville, Maryland, USA: MoHSS and ICF International; 2014.

[18] Ministry of Health and Social Services of Namibia. National policy for reproductive health. 2003. Namprint.

[19] Government of Namibia. Regulations relating to the scope of practice of persons registered or enrolled under the nursing act. No. 206. Windhoek. 2004. Namprint.

[20] World Health Organization. Medical Management of Abortion. Geneva: World Health Organization; 2019. Available from: https://apps.who.int/iris/bitstream/handle/106 65/278968/9789241550406-eng.pdf?ua=1 